\title{
Depth Neuromuscular Block in Laparoscopic Surgery: Usefulness In Laparoscopic Kidney Donation From Living Donor
}

\section{Dott.G.Consani*}

Department of Anesthesia and Intensive Care 1, A.O.U.P, Pisa, Italy

In the last years the surgical techniques have evolved and, in particular, laparoscopic and robotic surgeries have made a significant advantage compared to traditional surgery [1].

These techniques have brought up new issues related to the presence of pneumoperitoneum (generated by insufflation of $\mathrm{CO}_{2}$ ) that is crucial to optimize the abdominal cavity to ensure a good vision of the surgical field $[2,3]$.

The new challenge for the anesthetist is to deal with physiological changes determinated by pneumoperitoneum (haemodynamic, respiratory and renal alterations) which must be minimized in renal transplantation [4]; and at the same time guaranteeing the optimal working conditions for the surgeon, while keeping unchanged the safety parameters of the patient, in the intraoperative phase, during the awakening phase and the discharge from the surgical unit.

Thanks to the appearance on the market of new drugs in anesthesia, especially new curares (rocuromium bromide) and new antagonists (sugammadex) it is possible to improve the muscle relaxation and especially its resolution resulting in better effectiveness, efficiency and safety.

Therefore, today, optimizing muscle relaxation, the surgical space does not change also reducing $\mathrm{CO}_{2}$ insufflation pressure of $12-15$ $\mathrm{mmHg}$ to $10-8 \mathrm{mmHg}$ to create the pneumoperitoneum $[5,6]$

Several studies have demonstrated how deep neuromuscular relaxation can optimize the surgical field and reduce the pathophysiological changes due to $\mathrm{CO}_{2}$ insufflation [7].

To be mentioned Martini's study, where the authors evaluated the quality of surgical condition, as assessed by the surgeon, using a satisfaction scale (Surgical Rating Scale) between 1 and 5 (from extremely unfavorable to optimal condition). They have shown that in laparoscopic procedures, deep neuromuscular relaxation determines better surgical field conditions than a moderate neuromuscular relaxation.

Borg said that during laparoscopic kidney donation from living donor it is crucial to reduce pneumoperitoneum induced stress. This stress is dangerous for the patient and for the organ removed.

Today this can be obtained not only with an adequate volume expansion, which began on the evening before surgery and continued in the operating room $[8,9,10]$, but also with a deep neuromuscular relaxation that allows to reduce the intraperitoneal $\mathrm{CO}_{2}$ insufflation pressures to 10-8 mmhg maintaining a good surgical vision.

The deep neuromuscular block and the monitoring are crucial to reach this objective.

During the neuromuscular monitoring it is necessary to keep the Train Of Four (TOF) rates equal to zero and try to reach a Post Tetanic Count (PTC) lower than 5 twitches, that it is known to be the value to be reached to obtain an optimal deep neuromuscular block.

The problem of total recovery from neuromuscular blockade is now solved with the new reversal Sugammadex thanks to which the risks of Postoperative Residual Curarization (PORC) are avoided, and there is a rapid and immediate recovery from neuromuscular block [11].
This opportunity can ease the team work between anesthetist and surgeon, can reduce the problems related to the relaxation of the muscular wall and can give more security in the surgical field.

In this way, the surgeon can work in the best way, reducing the stress for the patients, eliminating the anesthetic issues of inadequate muscle relaxation, have a safe awakening and in the kidney laparoscopic donation protect the function of the organ removed.

\section{References}

1. Minnee RC1, Idu MM (2010) Laparoscopic donor nephrectomy. Neth J Med 68: $199-206$

2. Susan Midgley David A.Tolley (2006) Anaesthesia for laparoscopic Surgery in urology EAU -EBU Update series 241-245.

3. Gerges FJ1, Kanazi GE, Jabbour-Khoury SI (2006) Anesthesia for laparoscopy: a review. J Clin Anesth 18: 67-78.

4. Ingrid Mertens zur Borg (2008) Anaesthesia and peri-operative Care for Laparoscopic Donor Nephrectomy Department of Anaesthesiology, Erasmus University Medical Centre,Rotterdam, The Netherlands.

5. Martini CH1, Boon M, Bevers RF, Aarts LP, Dahan A (2014) Evaluation of surgical conditions during laparoscopic surgery in patients with moderate vs deep neuromuscular block. Br J Anaesth 112: 498-505

6. Staehr-Rye AK1, Rasmussen LS, Rosenberg J, Juul P, Gätke MR (2013) Optimized surgical space during low-pressure laparoscopy with deep neuromuscular blockade. Dan Med J 60: A4579.

7. John Vlot, Rene Wijnen, Robert Jan Stolker, Klaas Bax (2013) Optimizing working space in porcine laparoscopy: CT measurement of the effects of intraabdominal pressure." Surgical Endoscopy Volume 27, Issue 5, pp 1668-1673.

8. Biancofiore G , G Amorose , Lugli D , Bindi L, Esposito M , et al. (2004) Perioperative anesthetic management for laparoscopic kidney donation". Transplant Proc 36: 464-466

9. Mertens zur Borg IR1, Kok NF, Lambrou G, Jonsson D, Alwayn IP, et al. (2007) Beneficial effects of a new fluid regime on kidney function of donor and recipient during laparoscopic v open donor nephrectomy. J Endourol 21: 1509-1515.

10. Astrid Lindekaer, Olav Istre, Henrik Springborg, Aleris-Hamlet Ospedal privati, Soeborg Soeborg. Danimarca " Deep Neuromuscular Blockade Give the Same Intraabdominal Volume at $8 \mathrm{~mm} \mathrm{Hg}$ as No Blockade at $12 \mathrm{~mm} \mathrm{Hg}$ During Laparoscopy" Anesthesiology 2012 Congress of the American Society of Anesthesiologists Washington D.C. October 13-17 2102, Abstract a627.

11. Hans D de Boer (2009) Sugammadex: A New Challenge in Neuromuscular Management Adv Anaesthesiol Crit Care 1:20-25.

*Corresponding author: Dott.G.Consani, Department of Anesthesia and Intensive Care 1, A.O.U.P, Pisa, Italy, Tel: 39050 992111, E-mail: giovanniconsani@alice.it

Received March 05, 2014; Accepted April 25, 2014; Published May 03, 2014

Citation: Consani DG (2014) Depth Neuromuscular Block in Laparoscopic Surgery: Usefulness In Laparoscopic Kidney Donation From Living Donor. Surgery Curr Res 4: 188. doi:10.4172/2161-1076.1000188

Copyright: (c) 2014 Consani DG, et al. This is an open-access article distributed under the terms of the Creative Commons Attribution License, which permits unrestricted use, distribution, and reproduction in any medium, provided the original author and source are credited. 